\title{
Strategic Drift and Strategic Crisis Management of Organization
}

\author{
Tzveta Zafirova \\ University of Economics, Varna, Bulgaria
}

\begin{abstract}
The research reports how the choice of the organization behavior - strategic drift can lead to strategic crisis as a form of manifestation of a deepening organizational crisis. The research questions whose solution is sought are connected with the relation of strategic drift—strategic crisis—strategic crisis management, in terms of whether the errors in the process of strategic management lead to organizational crises. The results of the historical analysis of the theoretical research and practice in this field show the interdependence among these processes and the reasons for strategic crisis in support of the concept of strategic crisis management and its implementation in business. The study outlines the evolution of the theory of strategic drift, as well as opinions of various scientists on the types of crises, which are perceived as a uniform classification and universal interpretation of the term "strategic crisis". The organization's "strategic drift" leads to serious organizational crisis which first form that strategic crisis. Practice shows that the management of market leaders often leads to complacency, choosing strategy stability. Soon, as a result of aggressive strategies or implemented innovations of their competitors, they lose their competitive position.
\end{abstract}

Keywords: strategic drift, strategic crisis, strategic crisis management

\section{Introduction}

Each organization in a certain moment of its development is faced in front of a crisis. It is a situation, in which a physical person, a group, or an organization, is not capable of coping with the usage of normal routine procedures (Booth, 1993). Or in practice, the crisis is a change — sudden or permanent - which originates an urgent problem and requires an immediate intervention for its solution (Lukey, 2007).

The crisis management is a comparatively new field in the management science. The investigation of management of crises aroused after large-scale industrial and ecological calamities in 1980 (Shrivastava, Mitroff, Miller, \& Miglan, 1980). After the appearance of the first book in this field-Crisis Management: Planning for the Inevitable (Fink, 1986), a lot of scientific publications are written. The practice proves the affirmation of Venette (2003), that the crisis is a process of transformation, when the old system cannot be maintained anymore. This means a necessity of a serious change in the strategic conduct of the organization.

The instruments of the strategic management give a solution of the problems, connected with identification of the crisis, its mastery and overcoming, the recovery and the successful development of the organization. But the strategic decisions are connected with the solution of the problem for going out of the crisis through the choice of appropriate strategies. Therefore, the fourth defining quality is the need for change.

In the last years in connection with the loss of the positions of leading world companies, it is more and more talked and written about the so-called strategic drift. The reason for the appearance of this phenomenon

Tzveta Zafirova, Ph.D., associate professor of Management, Varna University of Economics, Varna, Bulgaria.

Correspondence concerning this article should be addressed to Tzveta Zafirova, 77 Kniaz Boris str., 9002 Varna, Bulgaria. E-mail: tzveta_zafirova@ue-varna..bg. 
again is connected with notions from the methodology of the strategic management, and later also with the process of management of crises. Without an appropriate strategy, the organization may become uncompetitive within the framework of its environment and this leads to its unprofitability-namely this phenomenon is known as a strategic drift. When one organization does not function in harmony with its environment and begins to fail, the appropriate strategy is a way to remain competitive or an instrument to be forced to make a strategic change.

The purpose of the publication is to be investigated how the choice of a conduct of the organization strategic drift may lead to a strategic crisis as a form of manifestation of the deepening organizational crisis.

\section{Strategic Crisis as a First Form of the Organizational Crises}

In the specialized literature, there does not exist a uniform attitude regarding the notion "crisis" in the contemporary science, since the theory is far behind the practice in the field. The scientists suggest different interpretations, depending on the aspects, in which they investigate it. But they can be generalized in the following: The crisis is each event, which is or is expected to lead to an unstable and dangerous situation, to a critical moment, in which it should be made as a choice and taken as important decisions.

The levels of manifestation of the crises are global, state (national), organizational, and crises of the individuals. Each one of them has its characteristic peculiarities and forms of manifestation. In the last years, special attention is paid to the organizational crises, since they become more frequent because of the unstable, dynamic, and turbulent environment.

Hermann (1963) pointed already in 1963 that the crisis is an unusual phenomenon, which threatens the organization, requires a fast reaction for a short period of time, and is a threat for its basic values.

One of the best researchers in the field Fink (1986) argued that in contrast to the generally accepted understanding, the crisis may not at all costs be a bad phenomenon, it only is characterized by a certain degree of risk and insecurity.

The prominent scientists in the field of crisis management Shrivastava and Mitroff (1987) indicated that crises develop simultaneously through a chain of events in several areas in and outside the organization. The managers do not have at their disposal control on these situations and frequently they have very little time in order to react to them. That the usually strong pressure from the government, the agencies, media, and the public for urgent coping with the crisis and softening of the consequences should not be forgotten.

Mishra (1996) proved in his research that notwithstanding the result from the crisis - whether it is positive or negative, it depends on the nature of the organizational conduct during a crisis.

Seeger, Sellnow, and Ulmer (2003) generalized that the crisis has four determining specific peculiarities. They specified that the first three are unexpectedness (surprise), formation of insecurity, and threat. They adopted the affirmation of Venette (2003) that the crisis is a process of transformation, when the old system cannot be maintained anymore. Therefore the fourth characteristic according to them is the necessity of a change.

James and Gilliland (2013) suggested one summarized contemporary characterization of the crises in the organizations on the grounds of investigations of a big volume of specialized literature - the representation of the crises as a threat and an opportunity - the reason is that the distress makes the people look for a way out.

In depth despite that the definitions for the crisis differ between themselves, each one of them is based on the affirmation that the crisis is an event, which may drastically influence the ability of the organization to maintain itself in condition of equilibrium and/or to develop itself. 
In this aspect, a generalization may be drawn up as the following interpretation for a crisis of the organization - this is appearance of dramatic phenomena and processes in the external and/or internal environment, which has direct or indirect impact on it, when the used-up to this moment methods of management become ineffective and violate its capacity for living. On this basis for the surviving in conditions of a crisis, the returning towards the normal functioning of the system and its further development needs a change in the management and the organization as a whole.

Parallel with this, the crisis situations in the organizations must be considered not as a concentration of unfavorable events, but general regularity, which is innate of the market economy and the organizational development. Based on this, the management of the organization is obliged to have a direction towards preparation and prevention of a potential crisis.

The indicated generalizations as a basis for the investigation of the processes may be accepted, which pass in the organizations, connected with the crisis. But a special interest for their management is the changes, which occur from point of view of the crisis process. They display in different forms of manifestation of the crises.

\section{Forms of Manifestation of the Crises in the Organizations}

In order for the management of the organization to react duly, it is necessary to know the basic phases of the crisis process from point of view of its forms and manifestation. This shall help the making of right management decisions.

In the specialized literature, several specific forms of the crises are known, depending on the phases, through which they pass. Zgonnik (2010) drew the following forms, which are most frequently met in the specialized literature:

- Strategic crisis-which affects all components of the social-economic life. It acts, by rule, on long-term base and characterizes the efficiency of the actions of the manager in a strategic plan. The strategic crisis arises at the loss in the management of the strategic vision - an untimely change of the production, a refusal of transition towards new technologies or in new regions, reduction of the investments in new techniques, technologies or training of cadres and so on.

- The crisis of the success - which is observed at originating of losses in the organization in connection with the defects of the management, for example, as a result of decrease in the turnover, growth of the maintenance, lowering of the prices, and decrease of the turnover capital. The crisis of the success leads to consecutive lowering of the share of the equity in the sources of funds for the organization. At the first stage, the lowering is to the level of the statute capital, and further it may lead to negative values of the own sources of funds. This crisis is average-term as a time interval.

- Crisis of liquidity — at it the organization is incapable of paying off its debt obligations. As a result of this, it continues to work for a certain time, accumulating debts or shall be liquidated. This crisis has a short-term character. With it, the problems cannot be solved independently by the management of the organization.

Krystek (1987) differentiated the crisis of operative (it refers to business crises) and strategic. He defined the strategic crisis as mistakes in the finding out, identifying, and prognostication of changes in the environment. The operative crisis, according to him, most frequently shows decrease of the individual carrying out of the indexes of the business systems (for example, decrease of the incomes from sales, market share, profits, or loss of clients and so on). This classification is accepted by other scientists, such as Vrečko and Mulej (2012). 
Orehov, Baldin, and Gaponenko (2006) divided the crisis of the success into tactical crisis and crisis of the collateralization, and in this way they differentiated four forms of the crisis. They are characterized with the following peculiarities:

- Strategic crisis - when the organization does not react at the warning signals for a future crisis, it stays indifferent to the changes in the environment and loses the strategic orientation and direction.

- Tactical - the first serious symptoms of the crisis begin to manifest, but yet not affect seriously the financial condition: decrease of the market share, discharging of personnel, decrease of the capacity because of decrease of the growth of demand of the offered products and services, decrease of the profit and etc..

- Crisis of the collateralization - a loss of the financial stability, insolvency, the financial results evidence for this. The organization is in front of a threat of bankruptcy, which is not certainly irreversible as a process, looking for new sources of financing and so on.

- Crisis of the liquidity - if the financial status of the organization evidences for absence of real opportunities for recovering of its solvency, this may be a reason for preparing and applying of a procedure as per liquidation.

The form of the crises is directly connected with the process of their manifestation in different organizations. It specifies the management decisions the leaders shall take for their overcoming.

The importance of the crisis for the strategic development of the organizations is firstly investigated by the German scientist Krystek (1987). Vrečko and Mulej (2012) affirmed in their investigation that comparatively few scientists are engaged with the strategic crisis, as these usually are based on the definition of Krystek (1987). Krystek (1987), as pointed, differentiated in operative (it refers to business crises) and strategic, and gave the following interpretation: The strategic crisis is defined as mistakes in the finding out, identification, and prognostication of changes in the environment, which have direct or indirect influence on the future activities and the competitiveness of the business systems based on the incorrect determination of their strategic direction and its carrying out.

As Shrivastava and Mitroff (1987) affirmed, big parts of the crises are caused by previous mistakes in the process of strategic management. The conclusion is that the strategic crisis often is due to lack of a complete good target orientation and strategy, as well as the strategic thought for the future.

As a result of these, investigations may be displayed in the following definition for the strategic crisis: A state which as a result of wrong management, including strategic decisions and/or a change in the environment and appeared conditions, leads to violation of the stability of the system and affects all its elements.

The identification of the strategic crises on the grounds of the existing definitions for them often is a question of a subjective interpreting, which makes it difficult for elaboration and applying of the necessary measures for their solving. Towards the strategic crisis, it leads to the absence or the insufficient development of the system for strategic management of the organization, in particular the absence of a good object-oriented orientation and the lack of an elaborated and realized strategy, as well as the lack of control and valuation of its realization. In practice, again the bad management and the problems are reached, as a result.

On this base, the conclusion is that the strategic crisis in the organization appears, when the leaders lose the strategic direction - the long-term target orientation; they do not evaluate the lack of reaction of the occurred changes in the environment, which could lead to crisis situations and lose of its capacity for living.

\section{Concept of Strategic Drift}

One quite suitable definition of the notion is offered by one of the leading managers of Solvey and 
simultaneously a teacher in their business school - the strategic drift is a tendency in the strategies for gradual development on the basis of historical and cultural influences of organizations, which do not succeed to be in step with the changing environment. Or this means that the strategic drift is the condition, which arises when one organization quickly develops its strategy in a way, not in step with the changing environment. Consequently, it may be a result of the situation which causes a company's strategies to fail to address the strategic state of the organization, the organizational culture and history, which impede the organizational change. In such aspect, the organization does not manage to keep its strategic position, which leads to an organizational crisis and frequently is followed by a transformation or a bankruptcy (Hensmans, Johnson, \& Yip, 2012).

Many researchers explain the strategic drift with examples from the practice of organizations, which have been leaders in certain industries, lines of business, and even in world scale, but they have lost their competitive positions as a result of their strategic drift. The most common among their activity is the tremendous scales of operating, the clumsiness, self-complacency, and the insufficient adoption of the new-the lack of innovations.

For the first time, Johnson (1988) elaborated the concept for the strategic drift as a discrepancy between the changes in the strategy of the organization and the changes in the external environment. He began his investigations from the concept for the logical incrementalism - a philosophy of the management, which is based on the thesis that the strategies have not appeared on the basis of a single decision and they exist on the basis of taking less important decisions periodically. These decisions are not taken accidentally and logically through deep analyses and evaluations. Johnson affirmed that the managers build their views with the help of external stimuli and also their perception for the environment on the grounds of homogenous and well-grounded ideas. They are inclined to regulate stage by stage only the strategy of the organization, following unconsciously the preliminary vision, which they have formulated. This strategic approach towards the evolution would divert from the changes of the external environment, which would lead to the situation of a strategic drift in the organization (Johnson, 1988).

In this initial definition of the strategic drift, Johnson (1988) did explain neither the problems, with which the organization may face, nor the factors, which may lead to this. Besides, he was more inclined to adopt the explanation of the strategic drift like an internal problem (choice of the stage by stage development of the strategy), rather than the result of changes of the external environment.

A bit later, Handy (1989), one of the founders of London Business School and a prominent researcher in the field of organizational conduct, pointed in his concept about the two types of organizational changes that the first of them is the strategic drift, which he explained as a regular change in the strategy of the organization, diversions from the vision, which happens so skilful that it is not noticed and when this happens, it is quite late. He named the other change as a transformational change and determined it as a sudden and radical one, which usually is caused by interruptions. It is typically caused by discontinuities (or exogenous shocks) in the business environment. The point where a new trend is initiated is called a strategic inflection point by Grove (1996), a chairman of the Board of the Directors of Intel Corporation, that this is an event, which changes the way, in which is thought and acted. The inflection points may be the result of actions, undertaken by the organization, by actions, or by another subject, which has a direct influence on it. Grove (1996) explained in his investigation that the strategic inflection point is, when the proportion of the powers is moved from the old structure, from the old ways for action and competition towards new ones. This is the point, where the curve barely perceptible, but deeply changes. His comments on the question, when one organization reaches a 
strategic inflection point, confirm the thesis about the possible crises and the outcome from them. In the activity of the organization, continuously changes occur, some small, other big, some transitional, other representing the beginning of a new era. The organization must adapt to them and solve the problems, which they cause. But not all have the meaning of a strategic inflection. It comes slowly: Firstly, there are warning signals; and after this, thunder and bang trivially hint that the dynamics of the competition has changed (Grove, 1996). With these reasoning on the strategic drift, the strategic inflection point again is proved to put into practice of the methodology of the strategic management in the process of management of crises. According to the explanation of Grove (1996) about the strategic inflection, it is the point, in which the organization is in a crisis situation, in accordance with the cyclic model of the capacity for living of the system (Johnson, Scholes, \& Whittington, 2005). This point can be, according to him, barely perceptible or radical.

As a summary of the ideas of Grove (1996), it can be pointed that in fact a strategic drift is obtained, when the organization does not change its target orientation and strategy, despite the changes in the environment. The lack of this change is explained again with its organizational culture and its history as a part. The result from this shall be an organizational crisis, which obligatory passes through the first form — the strategic crisis.

The above article clearly explains that the strategic drift occurs when the original goals become vague and impertinent. Langeler (1992) explained from a theoretical point of view that actually the strategic drift happens, when the initial purposes become unclear. Then the strategies can no longer uphold the vision and consequently the vision needs to be changed to suit the strategy for good or bad. It no longer can maintain the vision and consequently it should be changed in order to correspond to the strategy. A robust strategy presupposes a well-thought out vision. The stable strategy supposes a well considered vision, only then it shall bring success to the organization. The scientist reckons that if the vision mis-matches with the ad-hoc strategy, decisions are made incrementally to fuel present strategy and not as a part of vision. To conclude, strategic drift is not necessarily bad. If faced with strategic drift, it is pertinent for the organization to correct its basics and identify whether it has fallen into vision trap or is actually striving the wrong path. Putting a square peg in a round hole will not help, the strategic drift is not obligatory bad.

Several years later, Duck (2003) described very emotionally and picturesquely what happens in practice with great part of the leaders on the market. Despite the whole painfulness, the crisis for the big organization may turn out to be the only way for identification of the most typical symptom of the stagnation: the self-complacency. The speech of one of the managers of a company is added, which has lost its competitive position of a leader: Former successes are the biggest enemy for our future flourishing. Or the basic mistakes, which lead to crises, are namely the organizational culture, history, narcissism, and the self-complacency especially among organizations, which were leaders or among the leading in certain industries and lines of business. This proves the connection of the concept for the strategic drift with the crises in the organizations and the self-complacency as one of the basic mistakes of the management, which is a reason for the following crisis situation. The author would illustrate the concept with the example portrayed in the article The Vision Trap by Langeler. With the agenda of catering to the demand for product, the primary motive to have fun, Mentor Graphics embarked its journey with a simple unarticulated vision to build something that people will buy.

Johnson et al. (2005) revised their concept couple of years later that the strategic drift is a progressive failure of the existing strategy, regarding the competitive position of the organization, and began to assign to 
the changes in the environment a more key role. Besides, they admitted that inability of the organizations to rationalize and cope with these mighty powers leads to the inevitable decrease of the productivity. Since then onward, they explained with two main factors in the situation of the strategic drift: The first one is the more and more complicated and dynamic external environment, and the second one is the short-sightedness of the leaders to admit that the done corrections of the strategies are no longer in condition to follow the changes in the external environment.

The influence of the paradigm for the strategic drift (Johnson et al., 2005) can mean that standing in front of the pressure for a change, the managers are trying to minimize the degree of obscurity and uncertainty, in front of which they are standing, as they are looking for what is familiar. This frequently leads to a result in incremental change and gradual change (first phase). Despite this, however, environmental change may not be gradual enough for incremental change to keep pace and the organization will get out of line with its environment which may result in strategic drift in which the organization's strategy gradually moves away from relevance to the forces at work in its environment. The changes in the environment cannot be gradual enough, in order to be synchronized with a gradual change in the organization-it shall go out from this line of its encirclement, it is possible and in a better direction. As a result, the strategic drift (second phase) occurs, in which the strategy of the organization gradually gets removed from the meaning of the powers, which act in its environment. Even the most successful companies may drift in this way.

Johnson et al. (2005) showed that even the most successful organizations may float along the stream in this way (third phase). This model of drift makes it more difficult. This pattern of drift is made more difficult to detect and reverse, because changes may achieve some short-term improvement in performance, thus tending to legitimise the action taken. It is possible to find a new beginning and turn the direction, since there can be achieved some short-term changes in the carrying out of the strategy, which shall lead to legalization of the undertaken actions. It is possible that after this the strategy for development is without a clear direction, as its further execution harms the organization. In the final reckoning, eventually, more transformational change is likely, if the demise of the organization is to be avoided. A transformational change is more probable, if it does not reach the death of the organization (a bankruptcy) (fourth phase) (Johnson et al., 2005).

The concept for the strategic drift continues to perfect itself in time. Dividing the factors as external and internal, Gilligan and Wilson (2009) brought out the potential factors, which cause the strategic drift. From point of view of the external environment, these are the changes in the structure of the market, the competitive environment, and the expectations of the users, and the changes which provoke the technological evolution. As internal factors, which lead to a strategic drift, they described the bad investments and the bad management, the control of the expenses, as well as the wasted management philosophy. These are the basic reasons, which have already been indicated, for organizational crises, all of which are resulted from the bad management.

Complementing the view of Johnson et al. (2005) about the strategic drift, Gilligan and Wilson (2009) introduced the notion of wear of the strategy. If the organization does not succeed to foresee early enough the external changes and later on to change its course of development, even the most successful strategies inevitably shall be wasted and shall lead to a failure. These affirmations prove the thesis about the strategic crisis in the organization.

Dwyer and Edwards (2009) and Danciu (2010), reckoned that the concept of Gilligan and Wilson is not so universal, since it refers only to the inactive organizations, which are not inclined to change their present 
winning strategies; they reckoned that the organizations, which are standing in front of future dramatic changes in the external environment, can react proactively to orientate towards strategic changes. As based on the crisis management, this means that the managements, after the receiving of warning signals for a forthcoming crisis, can do the respective strategic choice.

As to the explanation of Danciu (2010) of the strategic drift, he took out four groups of reasons: changes in the expectations and the necessities of the consumers, changes in the structure of the market and the competition, changes in the micro-environment, and changes in the organizational strategies. This means that as sources for the crisis, he indicated that the changes are in the external, as well as in the internal environment, which is confirmed by many other researchers.

\section{Conclusions}

As a summary from the different attitudes of scientists and practitioners in the field, the followings may be indicated:

(1) A diversion from the strategy is obtained, when one organization, even if it enjoys a significant success, reacts quite slowly to the changes in the environment and preserves its strategy, after it develops well. Once imposed its successful management model, its leaders persist to make changes, despite that its future tendencies become more and more inappropriate.

(2) In the new reality and a turbulent environment, the organizations are object of strategic crises, as they basically are results of changes in the environment, in the external as well as in the internal. Big part of the crises is caused by previous mistakes in the process of strategic management. The strategic organizational crises are often due to the lack of a complete strategy, as well as the strategic thinking about the future. They appear in practice, when the leaders lose the strategic direction.

(3) The concept for the strategic disintegration grounds the necessity of the dynamics in the strategic crisis management, of a new suitable crisis strategy for preservation of the capacity for living of the organization. But this does not mean any strategic change at all costs, and the precisely necessary for the certain organization and the crisis situation, in which it is found. Its purpose shall be to preserve the sustainability of the organization. Or the strategic conduct of the organizations in crises is connected with its returning to its condition of equilibrium.

(4) It is necessary for each organization to be familiar with the symptoms of the strategic drift, in order to preserve its strategic position, which has historical roots. This shall allow it to prevent or decrease the losses from one possible crisis. If the organization does not succeed to foresee some changes early enough, to react adequately to them and consequently to change its behavior, the most successful strategies inevitably shall waste and lead to a failure.

\section{References}

Booth, S. (1993). Crisis management strategy. Competition and change in modern enterprises. London: Routledge.

Danciu, V. (2010). The gravity law of marketing-A major reason for change to a better performance. Theoretical and Applied Economics, 4, 7-18.

Duck, J. (2003). Change monster. Reasons for the success and failure of organizational changes. Moscow: Alpina Publisher.

Dwyer, L., \& Edwards, D. (2009). Tourism product and service innovation to avoid strategic drift. International Journal of Tourism Research, 11, 321-335.

Fink, St. (1986). Crisis management: Planning for the inevitable. New York: Blackprint. 
Gilligan, C., \& Wilson, R. (2009). Strategic marketing planning. Amsterdam: Elsevier.

Grove, A. (1996). Only the paranoid survive: How to exploit the crisis points that challenge every company. New York: Crown Business.

Handy, C. (1989). The age of unreason. London: Hutchinson.

Hensmans, M., Johnson, G., \& Yip, G. (2012). Strategic transformation: Changing while winning. Basingstoke: Palgrave MacMillan.

Hermann, C. F. (1963). Some consequences of crisis which limit the viability of organizations. Administrative Science Quarterly, 8, 61-72.

James, R., \& Gilliland, B. (2013). Crisis intervention strategies. Boston: Cengage Learning.

Johnson, G., Scholes, R., \& Whittington, R. (2005). Exploring corporate strategy (7th ed.). Harlow: Pearson Education.

Johnson, G. (1988). Rethinking incrementalism. Strategic Management Journal, 9, 75-91.

Krystek, U. (1987). Unternehmungskrise: Beschreibung, Vermeidung und Bewältigung überlebenskritischer Prozesse in Unternehmungen. Wiesbaden: Gabler Verlag.

Langeler, G. (1992). The vision trap. Harvard Business Review, 70, 46-54.

Lukey, R. (2007). Crisis management: Predictions and overcome. Sofia: Classic and Style.

Mishra, A. (1996). Organizational responses to crisis: the centrality of trust. In R. M. Kramer, \& T. Tyler (Eds.), Trust in organizations. Newbury Park: Sage.

Orehov, V., Baldin, K., \& Gaponenko, N. (2006). Crisis management. Moscow: INFRA-M.

Pearson, C.\& Clair, J. (1998) Reframing Crisis Management. Academy of Management Review, 23, 59-76.

Seeger, M., Sellnow, T., \& Ulmer, R. (2003). Communication and organizational crisis. Westport: Greenwood Publ. Group.

Shrivastava, P., \& Mitroff, I. (1987). Strategic management of corporate crises. Columbia Journal of World Business, 22, 5-11.

Shrivastava, P., Mitroff, I., Miller, D., \& Miglan, A. (1988). Understanding industrial crises. Journal of Management Studies, 25 , 285-304.

Venette, S. (2003). Risk communication in a high reliability organization: APHIS PPQ's inclusion of risk in decision making. Ann Arbor: UMI Proquest Information and Learning.

Vrečko, I., \& Mulej, M. (2012). Mastering systems strategic crises to prevent business crises. Naše gospodarstvo, 58, 3-13.

Zgonnik, L. (2010). Crisis management. Moscow: Dashkov \& K. 